\title{
POTENCIAL PROTETIVO DA POLIDEXTROSE COMO AGENTE ENCAPSULANTE DE Bifidobacterium BB-12 ATRAVÉS DO PROCESSO DE MICROENCAPSULAÇÃO POR SPRAY DRYING
}

Tiago Silva ${ }^{1}$, Michelle Heck Machado², Silvani Verruck ${ }^{2}$, Renata Dias de Mello Castanho Amboni ${ }^{3}$, Elane Schwinden Prudencio ${ }^{4}$

${ }^{1}$ Universidade Federal de Santa Catarina, Departamento de Ciência e Tecnologia de Alimentos, Graduado em Ciência e Tecnologia de Alimentos

${ }^{2}$ Universidade Federal de Santa Catarina, Programa de Pós-graduação em Ciência dos Alimentos, Mestre em Ciência dos Alimentos

${ }^{3}$ Universidade Federal de Santa Catarina, Programa de Pós-graduação em Ciência dos Alimentos, Doutora em Química

${ }^{4}$ Universidade Federal de Santa Catarina, Programa de Pós-graduação em Ciência dos Alimentos e Engenharia dos Alimentos, Doutora em Ciência dos Alimentos

*E-mail para contato: elane.prudencio@ufsc.br

RESUMO - A microencapsulação é um processo no qual as células viáveis probióticas são incorporadas em uma matriz ou membrana de encapsulamento a fim de protegê-las contra fatores ambientais. Assim, o objetivo deste trabalho foi avaliar o efeito da microencapsulação de Bifidobacterium BB-12 pelo método de spray drying, utilizando como agente encapsulante o prebiótico polidextrose em associação ou não com leite em pó. A solução de alimentação com a adição do prebiótico polidextrose apresentou maior teor de sólidos totais

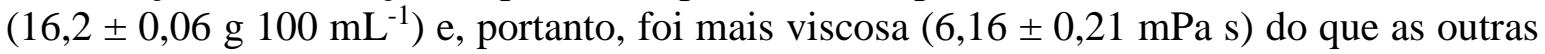
duas soluções. Apesar de ser confirmada a eficiência da microencapsulação de Bifidobacterium BB-12, com os agentes encapsulantes usados, através da análise da morfologia, foram observadas concavidades quando foi empregado leite desnatado. Em relação ao tamanho $(\leq 10,62 \pm 4,64 \mu \mathrm{m})$, ao teor de umidade $\left(\leq 3,10 \pm 0,20{\left.\mathrm{~g} 100 \mathrm{~g}^{-1}\right) \text { e à }}\right.$ atividade de água $(\leq 0,21 \pm 0,01)$, os três tipos de amostras produzidas estão de acordo com o indicado para este tipo de produto. Contudo, as amostras em pó contendo microcápsulas produzidas com a mistura de leite desnatado e polidextrose, como agente encapsulante, demonstraram maior densidade aparente $\left(0,70 \pm 0,03 \mathrm{~g} \mathrm{~mL}^{-1}\right)$, enquanto as produzidas somente com polidex trose dissolveram mais rapidamente em água $(224,37 \pm 14,19 \mathrm{~s})$ e foram

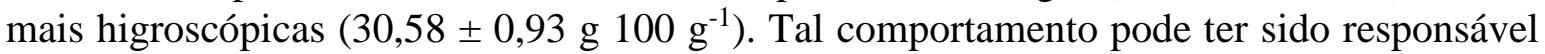
pela redução na contagem de bifidobactéria da amostra com microcápsulas produzidas com polidextrose $\left(8,46 \log\right.$ UFC $\left.\mathrm{g}^{-1}\right)$, apesar de não ter sido observada diferenças entre as contagens das três soluções de alimentação (entre 9,05 e 9,39 $\log \mathrm{UFC} \mathrm{g}^{-1}$ ). Ao final deste estudo, observou-se que as contagens de células viáveis de bifidobactéria, nas três amostras em pó, contendo microcápsulas produzidas com leite desnatado $\left(8,80 \log \mathrm{UFC} \mathrm{g}^{-1}\right)$, leite com polidextrose $\left(8,77 \log\right.$ UFC $\left.\mathrm{g}^{-1}\right)$ e somente polidextrose $\left(8,46 \log\right.$ UFC $\left.\mathrm{g}^{-1}\right)$, como agentes encapsulantes, ficaram acima do recomendado para um produto ser classificado como 
Recebido em:

$11 / 07 / 2018$

Aceito em:

$27 / 11 / 2018$

probiótico. Desta forma, pôde-se observar que o uso da polidextrose, como agente encapsulante de Bifidobacterium BB-12, apresentou potencial protetivo no processo de microencapsulação por spray drying.

Palavras-chave: Bifidobacterium BB-12. Polidextrose. Probióticos. Prebióticos. Microencapsulação. Spray drying.

DOI: $10.5965 / 24473650412018052$

\section{INTRODUÇÃO}

A mudança nos padrões de cuidados da saúde, o aumento na expectativa de vida e a busca por uma melhor qualidade de vida dos consumidores impulsionam o estudo e o desenvolvimento de alimentos funcionais (VASILJEVIC; SHAH, 2008), principalmente os enriquecidos com componentes fisiologicamente ativos, como os probióticos (ANNUNZIATA; VECCHIO, 2013). Probióticos são micro-organismos vivos que conferem benefícios à saúde de seu hospedeiro, quando administrados regularmente (FAO/WHO, 2006), em contagem de células viáveis igual ou maior do que $6 \log$ UFC $\mathrm{mL}^{-1}$ ou g ${ }^{-1}$ de produto (PERES et al., 2012). A ingestão regular de micro-organismos probióticos resulta em benefícios como o estímulo do sistema imunológico, a melhora na digestão de lactose e a inibição de patógenos intestinais (SHAH, 2007; PRASANNA; GRANDISON; CHARALAMPOPOULOS, 2014).

Dentre os micro-organismos probióticos, os pertencentes aos gêneros Lactobacillus e Bifidobacterium figuram como os mais empregados em alimentos (KARIMI; SOHRABVANDI; MORTAZAVIAN, 2012). Contudo, alguns fatores dos alimentos, como por exemplo, a presença de elevados teores de oxigênio, sal e ácidos podem limitar a funcionalidade destes micro-organismos (DE VOS et al., 2010; GRANATO et al., 2010). A fim de superar estas limitações, métodos de microencapsulação são aplicados aos micro-organismos probióticos, servindo como uma "barreira" física e, portanto, sendo uma proteção capaz de mantê-los vivos no alimento (KOMATSU; BURITI; SAAD, 2008), para serem liberados de forma viável e metabolicamente ativa no intestino (NAZARRO et al., 2012). Os métodos de microencapsulação consistem no empacotamento de materiais sólidos, líquidos ou gasosos em microcápsulas, as quais podem liberar o conteúdo de forma controlada e em condições específicas (ANAL; STEVENS, 2005). Dentre estes métodos o spray drying tornou-se importante para produtos e/ou micro-organismos que apresentam sensibilidade ao calor, como os probióticos, devido à sua versatilidade e ao pequeno tempo de residência destes na câmara de secagem (ROKKA; RANTAMÄKI, 2010; YING et al., 2010). O material a ser encapsulado é denominado núcleo ou material ativo, enquanto o que forma o revestimento é chamado de material de parede, carreador ou agente encapsulante (MADENE et al., 2006). Entretanto, a estabilidade das microcápsulas obtidas requer a combinação de agentes encapsulantes adequados junto a fatores físicos empregados no método spray drying (ANANTA; VOLKERT; KNORR, 2005).

Os probióticos podem ser protegidos pelo método de spray drying utilizando-se uma série de agentes encapsulantes, incluindo alguns carboidratos, como por exemplo, os prebióticos (CORCORAN et al., 2004; ANANTA; VOLKERT; KNORR, 2005; CHEN et al., 2005). Estudos envolvendo o emprego de prebióticos como material encapsulante na produção de microcápsulas probióticas relatam 
a eficiência na promoção da sua estabilidade, bem como a manutenção destes micro-organismos protegendo-os contra métodos agressivos de processamento (FRITZEN-FREIRE et al., 2012b; PINTO et al., 2012; OKURO et al., 2013).

Prebióticos são fibras alimentares solúveis resistentes às enzimas digestivas, não digeríveis pelo organismo humano, chegando intactos ao intestino grosso, onde são fermentados por bifidobactérias presentes no cólon (ROBERFROID, 2007). Dentre os prebióticos, tem-se a polidextrose, que é uma preparação comercial obtida a partir da glicose, sorbitol e ácido cítrico, com grau de polimerização entre 10 e 12. Devido ao potencial sinérgico entre probióticos e prebióticos, a combinação destes ingredientes é definida como simbiótica, a qual beneficia ainda mais o hospedeiro devido ao aumento da sobrevivência e implantação dos micro-organismos vivos no sistema gastrintestinal (CASIRAGHI et al., 2007).

Como as propriedades físicas das microcápsulas variam com tipo de agente encapsulante empregado, Fávaro-Trindade, Pinho e Rocha (2008) ressaltam que avaliações das propriedades físicas das microcápsulas são necessárias. Desta forma, como pesquisas envolvendo a caracterização e a manutenção de concentrações adequadas do micro-organismo probiótico Bifidobacterium BB-12 microencapsulado com polidextrose pelo método de spray drying são inexistentes, a realização deste trabalho se justifica. Portanto, o objetivo deste trabalho foi avaliar o efeito da microencapsulação de Bifidobacterium BB-12 pelo método de spray drying, utilizando como agente encapsulante o prebiótico polidextrose.

\section{MATERIAL E MÉTODOS}

\subsection{Material}

A cultura probiótica liofilizada contendo Bifidobacterium BB-12 ${ }^{\circledR}$ (BB-12 ${ }^{\circledR}$, Chr. Hansen, Hónsholm, Dinamarca) foi utilizada como material ativo para as microcápsulas. Os agentes encapsulantes utilizados foram leite em pó desnatado comercial (Molico ${ }^{\circledR}$, Nestlé, São Paulo, Brasil) e o prebiótico polidextrose (STA-LITE ${ }^{\circledR}$ III, Tate \& Lyle, Ilinóis, EUA) com grau de polimerização (GP) entre 10 e 12. As análises microbiológicas foram realizadas com Ágar MRS (Difco ${ }^{\circledR}$, Sparks, EUA), cloreto de lítio (Vetec ${ }^{\circledR}$, Rio de Janeiro, Brasil), propionato de sódio (Fluka ${ }^{\circledR}$, Neu-Ulm, Alemanha) e AnaeroGen ${ }^{\circledR}$ (Oxoid, Hampshire, Reino Unido). Todos os reagentes químicos empregados foram de grau analítico.

\subsection{Microencapsulação pelo método spray drying}

A cultura de Bifidobacterium BB-12 (2,5 g $\left.100 \mathrm{~mL}^{-1}\right)$ foi primeiramente reidratada no leite em pó desnatado reconstituído em água destilada estéril $\left(12,5 \mathrm{~g} 100 \mathrm{~mL}^{-1}\right)$, congelada e mantida a $-19 \pm 1$ ${ }^{\circ} \mathrm{C}$ em frascos estéreis até a sua utilização, sendo posteriormente descongelada, resultando em uma suspensão de bifidobactéria com contagem de células viáveis inicial de 10,93 log UFC g ${ }^{-1}$.

Três diferentes amostras em pó, contendo bifidobactéria microencapsulada foram obtidos a partir das seguintes soluções de alimentação: (a) leite desnatado reconstituído a uma concentração de $20 \mathrm{~g}$ por $100 \mathrm{~mL}$ de água destilada, (b) $10 \mathrm{~g}$ de leite desnatado e $10 \mathrm{~g}$ de polidextrose por $100 \mathrm{~mL}$ de água destilada, e (c) $20 \mathrm{~g}$ de polidextrose por $100 \mathrm{~mL}$ de água destilada, que foram denominadas de 
Recebido em:

$11 / 07 / 2018$

Aceito em:

$27 / 11 / 2018$

controle, A1 e A2, respectivamente. Todas estas soluções foram tratadas a $80 \pm 1{ }^{\circ} \mathrm{C}$ por 30 minutos e resfriadas até a temperatura ambiente.

Cada uma dessas soluções de alimentação foi inoculada com a suspensão de bifidobactéria (6 mL da suspensão em cada $100 \mathrm{~mL}$ da solução de alimentação) e avaliadas quanto ao teor de sólidos totais $\left(\mathrm{g} 100 \mathrm{~mL}^{-1}\right)$, densidade $\left(\mathrm{g} \mathrm{cm}^{-3}\right)$ e viscosidade (mPa s). As soluções inoculadas foram submetidas à microencapsulação pelo método spray drying, realizado em equipamento spray dryer modelo B-290 (Buchi, Flawil, Suíça), utilizando ar de secagem com temperatura de entrada de $150 \pm 2{ }^{\circ} \mathrm{C}$ e de saída de $55 \pm 3{ }^{\circ} \mathrm{C}$. Durante esta operação de secagem as três soluções de alimentação contendo a suspensão de Bifidobacterium BB-12 (controle, A1, A2) foram mantidas em temperatura ambiente com agitação usando agitador magnético modelo DI 03 (Dist, Santa Catarina, Brasil) até a entrada na câmara principal do spray dryer, realizada com auxílio de bomba peristáltica com fluxo de alimentação de 6 $\mathrm{mL} \min ^{-1}$, taxa de alimentação do fluxo de ar quente igual $35 \mathrm{~m}^{3} \mathrm{~h}^{-1}$ e pressão do compressor de ar igual a $0,7 \mathrm{mPa}$. Cada uma das três amostras em pó foi coletada na base do ciclone do equipamento de secagem e misturada com auxílio de uma espátula, sendo denominadas de MC, M1 e M2, para as provenientes da solução de alimentação inoculadas com a suspensão de bifidobactéria controle, A1 e A2, respectivamente.

A fim de avaliar o efeito da microencapsulação de Bifidobacterium BB-12 pelo método de spray drying, utilizando como agente encapsulante a polidextrose, as amostras em pó (MC, M1, M2) foram avaliadas em relação às seguintes propriedades físicas: morfologia, tamanho das partículas, teor de umidade, atividade de água, densidade aparente, dissolução em água e higroscopicidade. Todo o experimento e análises foram realizados em triplicata, exceto as análises de determinação da morfologia e do tamanho de partículas que foram realizadas uma única vez. A contagem de células viáveis de bifidobactéria (log de Unidade Formadora de Colônia por $g$ de amostra, $\log \mathrm{UFC}^{-1}$ ) foi realizada em triplicata nas três soluções de alimentação, contendo a suspensão de bifidobactéria (controle, A1, A2), e nas amostras em pó obtidas pelo método spray drying (MC, M1, M2).

\subsection{Características das soluções de alimentação}

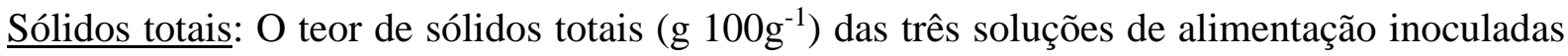
com bifidobactéria (controle, A1, A2) foram realizadas através da secagem em estufa a $105 \pm 1{ }^{\circ} \mathrm{C}$ por 3,5 horas, cujo valor obtido foi diminuído de 100, de acordo com o Manual de Normas Analíticas do Instituto Adolfo Lutz (IAL, 2008).

Densidade: A densidade das soluções de alimentação (controle, A1, A2) foi obtida através de um picnômetro previamente equilibrado até a massa constante a $25{ }^{\circ} \mathrm{C}$, conforme a seguinte equação descrita por Avila-Reyes et al. (2014):

$$
\rho_{\mathrm{s}}=\frac{\left(\mathrm{m}_{3}-\mathrm{m}_{1}\right)}{\left(\mathrm{m}_{2}-\mathrm{m}_{1}\right) \times \rho_{\mathrm{H}_{2} \mathrm{O}}}
$$

onde $\rho_{\mathrm{s}}$ é a densidade da solução de alimentação $m_{1}$ a massa do picnômetro vazio $(\mathrm{g}), m_{2}$ a massa do picnômetro preenchido com água $(\mathrm{g}), m_{3}$ a massa do picnômetro com a solução $(\mathrm{g})$ e $\rho_{\mathrm{H}_{2} \mathrm{O}}$ a densidade da água $\left(\mathrm{g} \mathrm{cm}^{-3}\right)$.

Viscosidade: A viscosidade das soluções de alimentação (controle, A1, A2) foi determinada através do viscosímetro de queda de bola Höppler modelo B3 (VEB MLW, Lesskestrabe, Alemanha), 
seguindo a metodologia descrita por Palczewska-Tulinska e Oracz (2005), com modificações. Os tempos (s) gastos pela esfera de acrílico ao percorrer uma distância $(\mathrm{cm})$ no viscosímetro a $25^{\circ} \mathrm{C}$ foi anotado e a viscosidade de cada solução de alimentação foi calculada de acordo com a equação 2 :

$$
\tau=t\left(\rho_{1}-\rho_{2}\right) K
$$

onde $\tau$ é a viscosidade da solução de alimentação ( $\mathrm{mPa} \mathrm{s}$ ), $t$ o tempo de escoamento da esfera na solução de alimentação no viscosímetro (s), $\rho_{1}$ a densidade da esfera $\left(\mathrm{g} \mathrm{cm}^{-3}\right), \rho_{2}$ a densidade da solução $\left(\mathrm{g} \mathrm{cm}^{-3}\right)$ e $K$ a constante da esfera empregada no viscosímetro $\left(\mathrm{mPa} \mathrm{cm}^{-3} \mathrm{~g}^{-1}\right)$.

\subsection{Propriedades físicas das amostras em pó}

Morfologia e tamanho das partículas: A morfologia e o tamanho das partículas foram realizadas em microscópio eletrônico de varredura modelo JSM 6390 LV (Jeol, Tóquio, Japão) em uma voltagem de 10 e $15 \mathrm{kV}$. As amostras em pó (MC, M1, M2) foram previamente colocadas em papel adesivo e revestidas de ouro com um revestidor de pulverização catódica sob vácuo modelo EM SCD 500 (Leica, Wetzlar, Alemanha), como descrito por Lian, Hsiao e Chou (2002). Para calcular seu diâmetro, foram medidas pelo menos 120 microcápsulas (KRASAEKOOPT; BHANDARI; DEETH, 2004) a partir de 4 micrografias obtidas para cada uma das amostras em pó (MC, M1, M2).

Teor de umidade: $\mathrm{O}$ teor de umidade $\left(\mathrm{g} 100 \mathrm{~g}^{-1}\right)$ das amostras MC, M1 e M2 foi determinado através de secagem em estufa a $105 \pm 1{ }^{\circ} \mathrm{C}$ até obtenção do valor da massa constante, como descrito pelo Manual de Normas Analíticas do Instituto Adolfo Lutz (IAL, 2008).

Atividade de água: A atividade de água foi mensurada usando um analisador modelo AquaLab Series 4TE (Decagon Devices, São Paulo, Brasil) após as amostras MC, M1 e M2 serem estabilizadas a $25^{\circ} \mathrm{C}$ por $30 \mathrm{~min}$.

Densidade aparente: $\mathrm{O}$ cálculo da densidade aparente foi realizado segundo a metodologia proposta por Avila-Reyes et al. (2014) através da equação 3, empregando um tubo de ensaio preenchido com as amostras MC, M1 e M2.

$$
\rho_{m}=\frac{m_{T^{-}-m}}{\mathrm{~V}}
$$

onde $\rho_{m}$ é a densidade aparente $\left(\mathrm{g} \mathrm{mL}^{-1}\right), m_{T}$ é o somatório da massa (g) da amostra em pó (contida num determinado volume do tubo de ensaio) e a massa deste tubo de ensaio vazio, $m$ é a massa (g) do tubo de ensaio vazio e $V(\mathrm{~mL})$ o volume preenchido pela amostra em pó, que foi igual a $10 \mathrm{~mL}$.

Dissolução em água: A dissolução foi realizada pela adição de $2 \mathrm{~g}$ das amostras em pó MC, M1 e M2 em $50 \mathrm{~mL}$ de água destilada (EL-TINAY; ISMAIL, 1985). Em um béquer (100 mL) a mistura foi agitada utilizando uma barra agitadora de $3 \mathrm{~mm} \times 6 \mathrm{~mm}$ de dimensão e um agitador magnético modelo DI 03 (Dist, Santa Catarina, Brasil) a 892 rpm. O tempo necessário para dissolução completa das amostras foi anotado.

Higroscopicidade: A higroscopicidade foi determinada de acordo com o método proposto por Cai e Corke (2000), com modificações. Cerca de $1 \mathrm{~g}$ de cada uma das amostras (MC, M1, M2) foi colocada em dessecador $\left(25 \pm 1^{\circ} \mathrm{C}\right)$ contendo solução saturada de cloreto de sódio (resultando em uma 
umidade relativa de 75,3\%). Após uma semana, as amostras foram pesadas e sua higroscopicidade foi

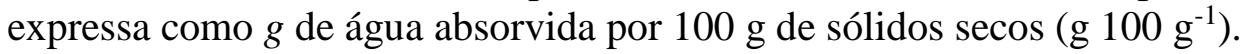

\subsection{Contagem de Bifidobacterium BB-12}

A contagem de bifidobactéria foi determinada nas amostras das soluções de alimentação contendo suspensão bacteriana (controle, A1, A2) e nas amostras em pó (MC, M1, M2). Entretanto, para determinar a contagem de bifidobactérias aprisionadas nas microcápsulas, elas foram primeiramente liberadas de acordo com o método proposto por Kim et al. (2008), com modificações. Neste método, 0,1 g de cada uma das amostras em pó (MC, M1, M2) foram suspendidas em 0,9 mL de solução tampão fosfato $\left(0,1 \mathrm{~mol} \mathrm{~L}^{-1}, \mathrm{pH} 7,0\right)$, seguida de agitação em agitador magnético modelo DI 03 (Dist, Santa Catarina, Brasil) por 10 minutos. As amostras em pó suspendidas e as amostras das soluções de alimentação (controle, A1, A2) foram serialmente diluídas em água peptonada (0,1 g 100 $\mathrm{mL}^{-1}$ ) e plaqueadas pelo método de profundidade em ágar MRS modificado com a adição de cloreto de lítio $\left(0,2 \mathrm{~g} 100 \mathrm{~mL}^{-1}\right)$ e propionato de sódio $\left(0,3 \mathrm{~g} 100 \mathrm{~mL}^{-1}\right)$, como proposto por Vinderola e Reinheimer (1999). As placas foram incubadas em jarras anaeróbicas contendo AnaeroGen ${ }^{\circledR}$ (Oxoid, Hampshire, Reino Unido) a $37,0 \pm 0,1{ }^{\circ} \mathrm{C}$ por 72 horas. Após o período de incubação, a contagem de bifidobactéria foi realizada e expressa em $\log \mathrm{UFC}^{-1}$.

\subsection{Análise estatística}

Os resultados obtidos foram analisados através do software STATISTICA 13.3 (TIBCO, Palo Alto, CA, EUA). A análise de variância (ANOVA) foi aplicada para determinar as diferenças significativas $(\mathrm{p}<0,05)$ entre as amostras, seguida pelo teste de Tukey.

\section{RESULTADOS E DISCUSSÃO}

\subsection{Caracterização das soluções de alimentação}

Os resultados para a caracterização das soluções de alimentação (Controle, A1, A2) estão apresentados na Tabela 1. Pôde-se verificar que a utilização somente da polidextrose contribuiu para o aumento $(\mathrm{p}<0,05)$ dos valores de sólidos totais e, para a viscosidade. Este resultado indica que a polidextrose resulta em maiores gotículas de aerossóis, dentro da câmara principal do spray dryer, diminuindo a superfície de contato destas com o ar quente. Segundo Lian, Hsiao e Chou (2002) e BáezGonzalez et al. (2004) tal fato poderia gerar danos ao micro-organismo microencapsulado. Entretanto, Osorio et al. (2014) relataram que o tempo de exposição (segundos) das gotículas com o ar quente, pelo método de spray drying, não reduziria drasticamente a contagem de micro-organismos microencapsulados. Os valores da densidade das três soluções de alimentação não diferiram ( $\mathrm{p}>0,05)$. O mesmo comportamento foi verificado por Avila-Reyes et al. (2014) para soluções de alimentação contendo 10,15 e $20 \mathrm{~g} 100 \mathrm{~mL}^{-1}$ de amido de arroz nativo e inulina respectivamente. 
Recebido em:

$11 / 07 / 2018$

Aceito em:

$27 / 11 / 2018$

Tabela 1 - Resultados da caracterização das soluções de alimentação

\begin{tabular}{cccc}
\hline Soluções de alimentação & $\begin{array}{c}\text { Sólidos totais } \\
\left(\mathbf{g} \mathbf{~ 1 0 0} \mathbf{~ m L}^{-\mathbf{1}}\right)\end{array}$ & $\begin{array}{c}\text { Densidade } \\
\left(\mathbf{g ~ c m}^{-\mathbf{3}}\right)\end{array}$ & Viscosidade (mPa s) \\
\hline Controle & $15,5 \pm 0,12^{\mathrm{b}}$ & $1,0664 \pm 0,0012^{\mathrm{a}}$ & $2,77 \pm 0,01^{\mathrm{b}}$ \\
A1 & $15,7 \pm 0,06^{\mathrm{b}}$ & $1,0669 \pm 0,0001^{\mathrm{a}}$ & $2,13 \pm 0,02^{\mathrm{c}}$ \\
A2 & $16,2 \pm 0,06^{\mathrm{a}}$ & $1,0693 \pm 0,0018^{\mathrm{a}}$ & $6,16 \pm 0,21^{\mathrm{a}}$ \\
\hline
\end{tabular}

Resultados expressos como média \pm desvio padrão, realizado em triplicata para cada experimento.

${ }^{a, b, c}$ Letras minúsculas diferentes sobrescritas na mesma coluna indicam diferenças $(p<0,05)$ entre as médias das soluções de alimentação.

Controle: leite desnatado reconstituído a uma concentração de $20 \mathrm{~g}$ por $100 \mathrm{~mL}$ de água destilada. A1: $10 \mathrm{~g}$ de leite desnatado e $10 \mathrm{~g}$ de polidextrose por $100 \mathrm{~mL}$ de água destilada. A2: $20 \mathrm{~g}$ de polidextrose por 100 $\mathrm{mL}$ de água destilada.

Fonte: elaborado pelo autor (2018).

\subsection{Propriedades físicas das amostras em pó}

A Figura 1 (a, b, c, d, e, f) mostra as micrografias das microcápsulas de Bifidobacterium BB-12 produzidas pelo método de spray drying empregando leite, leite com polidextrose e somente a polidextrose, como agentes encapsulantes. A partir desta figura não foi possível notar a presença de bifidobactérias fora das microcápsulas formadas, apresentando-se sem rupturas, confirmando a eficiência do método de microencapsulação, assim como dos agentes encapsulantes utilizados. Entretanto, nas amostras em que foi utilizado leite em pó foram observados concavidades (Figura 1 a, b). Fávaro-Trindade et al. (2010) relatam que este tipo de estrutura é característica de alguns produtos submetidos ao método spray drying em decorrência da rápida evaporação do líquido.

O tamanho das microcápsulas obtidas (Tabela 2) está de acordo com o recomendado por Fang e Bandari (2010) que indicam como ideais diâmetros entre 10 e $100 \mu \mathrm{m}$. Resultados similares foram obtidos por Fritzen-Freire et al. (2012a) que produziram microcápsulas com tamanhos entre 14,45 e $18,78 \mu \mathrm{m}$, empregando como agentes encapsulantes leite desnatado e prebióticos.

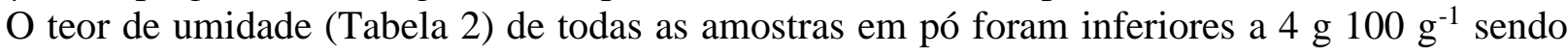
este, de acordo com Heidebach, Först e Kulozik (2010), o limite máximo indicado na manutenção da estabilidade das microcápsulas. Já o valor indicado para a atividade de água de micro-organismos microencapsulados deve ser inferior a 0,3. Desta forma, também na Tabela 2 pode-se verificar que estes valores ficaram entre 0,11 e 0,21. Gomes et al. (2007) e Soukoulis et al. (2014) relataram que durante prolongado período de armazenamento, a polidextrose influenciaria na estabilidade física do alimento e, segundo Tonon et al. (2009) nas suas reações bioquímicas. Resultados similares para a atividade de água foram verificados por Castro-Cislaghi et al. (2012) e Fritzen-Freire et al. (2012a), ao avaliarem a microencapsulação de Bifidobacterium BB-12 com soro de leite e com diferentes prebióticos, respectivamente.

As amostras em pó contendo somente leite desnatado (MC) ou somente polidextrose (M2) apresentaram os menores valores $(\mathrm{p}>0,05)$ para a densidade aparente (Tabela 2). Já a dissolução foi mais rápida $(\mathrm{p}<0,05)$ para a amostra em pó com polidextrose $(\mathrm{M} 2)$, seguida da $\mathrm{M} 1 \mathrm{e}$ da $\mathrm{MC}(\mathrm{p}<0,05)$. Pinto et al. (2015) afirmaram que um maior tempo para a dissolução da microcápsula conferiria maior 
estabilidade ao probiótico e, portanto, maior contagem de células viáveis. Também como Pinto et al. (2015) foi verificada maior higroscopicidade para as amostras em pó contendo polidextrose, o que poderia resultar numa menor estabilidade das microcápsulas, o que também reduziria a contagem de células viáveis de bifidobactéria. Tal comportamento foi confirmado por Gomes et al. (2007) que observaram alta dissolução da polidextrose em água, enquanto Vissoto, Gomes e Batista (2005) e Aidoo et al. (2013) observaram maior higroscopicidade de produtos contendo polidextrose.

Figura 1 - Micrografias das microcápsulas de Bifidobacterium BB-12 com leite desnatado (a, b), leite desnatado e polidextrose (c.d) e somente polidextrose (e,f), com magnitudes empregadas de $1.000 \mathrm{X}$ (a, c, e) e $5.000 \mathrm{X}(\mathrm{b}, \mathrm{d}, \mathrm{f})$. A seta branca demonstra a presença de concavidades nas microcápsulas

(a)

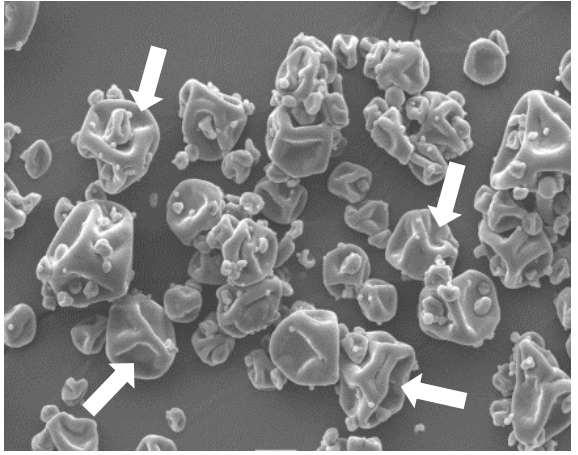

(c)

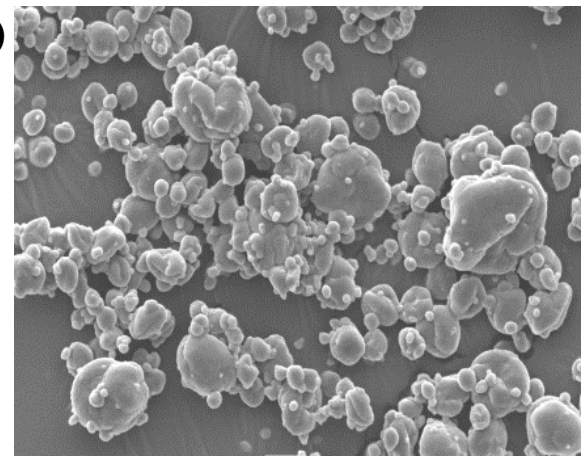

(e)

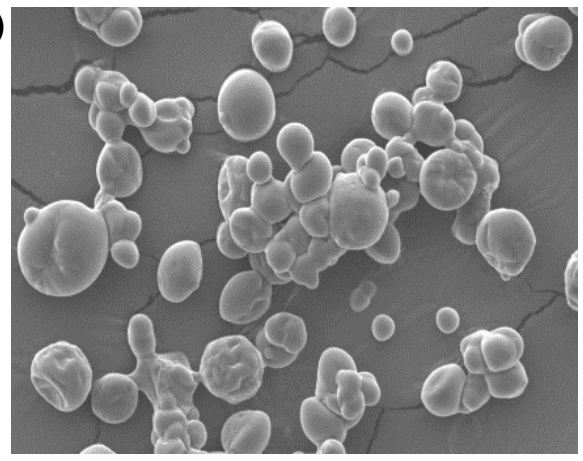

(b)

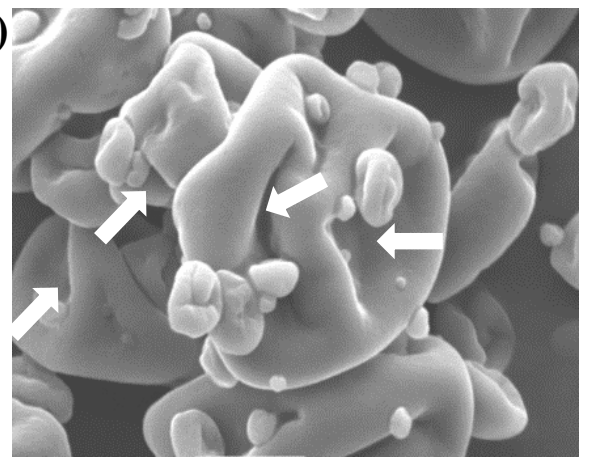

(d)

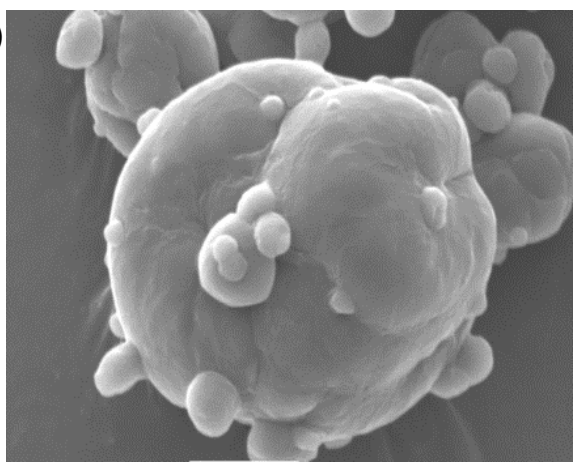

(f)

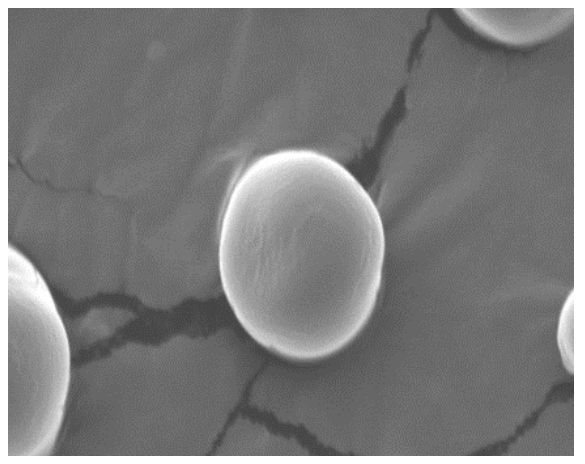

Fonte: elaborado pelo autor (2018). 
Recebido em:

$11 / 07 / 2018$

Aceito em:

$27 / 11 / 2018$

Tabela 2 - Propriedades físicas das amostras em pó obtidas pelo método de spray drying

\begin{tabular}{lccc}
\hline & \multicolumn{3}{c}{ Amostras em pó } \\
\cline { 2 - 4 } & MC & M1 & M2 \\
\hline Tamanho da partícula $(\boldsymbol{\mu m})$ & $10,62 \pm 4,64^{\mathrm{a}}$ & $10,69 \pm 3,62^{\mathrm{a}}$ & $10,65 \pm 3,23^{\mathrm{a}}$ \\
Umidade $\left(\mathbf{g} \mathbf{1 0 0} \mathbf{g}^{-1}\right)$ & $3,00 \pm 0,17^{\mathrm{a}, \mathrm{b}}$ & $3,10 \pm 0,20^{\mathrm{a}}$ & $2,60 \pm 0,11^{\mathrm{b}}$ \\
Atividade de água & $0,13 \pm 0,01^{\mathrm{b}}$ & $0,21 \pm 0,01^{\mathrm{a}}$ & $0,11 \pm 0,01^{\mathrm{b}}$ \\
Densidade aparente $\left(\mathbf{g} \mathbf{~ m L}^{-1}\right)$ & $0,58 \pm 0,01^{\mathrm{b}}$ & $0,70 \pm 0,03^{\mathrm{a}}$ & $0,61 \pm 0,02^{\mathrm{b}}$ \\
Dissolução em água $(\mathbf{s})$ & $949,43 \pm 25,68^{\mathrm{a}}$ & $795,33 \pm 22,74^{\mathrm{b}}$ & $224,37 \pm 14,19^{\mathrm{c}}$ \\
Higroscopicidade $\left(\mathbf{g} \mathbf{1 0 0} \mathbf{g}^{-1}\right)$ & $15,67 \pm 1,07^{\mathrm{c}}$ & $23,70 \pm 3,17^{\mathrm{b}}$ & $30,58 \pm 0,93^{\mathrm{a}}$ \\
\hline
\end{tabular}

Resultados expressos como média \pm desvio padrão, realizado em triplicata para cada amostra em pó.

${ }^{a, b, c}$ Letras minúsculas diferentes sobrescritas na mesma linha indicam diferenças $(\mathrm{p}<0,05)$ entre as médias das amostras em pó.

MC: amostra em pó da solução de alimentação contendo leite desnatado reconstituído a uma concentração de 20 g por $100 \mathrm{~mL}$ de água destilada, inoculada com bifidobactéria. M1: amostra em pó da solução de alimentação contendo $10 \mathrm{~g}$ de leite desnatado e $10 \mathrm{~g}$ de polidextrose por $100 \mathrm{~mL}$ de água destilada, inoculada com bifidobactéria. M2: amostra em pó da solução de alimentação contendo $20 \mathrm{~g}$ de polidextrose por $100 \mathrm{~mL}$ de água destilada, inoculada com bifidobactéria.

Fonte: elaborado pelo autor (2018).

\subsection{Contagem de células viáveis de Bifidobacterium BB-12}

A Tabela 3 apresenta os resultados da contagem de células viáveis das bifidobactérias inoculadas nas soluções de alimentação (Controle, A1 e A2) e amostras em pó obtidas pelo processo de microencapsulação (MC, M1 e M2). A contagem nas soluções de alimentação não apresentaram diferenças ( $\mathrm{p}<0,05)$. Estes valores estão de acordo com aqueles recomendados por Ross et al. (2005) e Vinderola et al. (2009) para soluções de alimentação que serão submetidas a secagem em spray dryer. Em relação às amostras em pó obtidas pelo método de spray drying, verificou-se que o uso do leite conferiu maior proteção $(\mathrm{p}<0,05)$ para bifidobactéria. Comparando as soluções de alimentação e suas respectivas amostras em pó, verificou-se que somente o emprego de polidextrose conferiu a menor proteção para bifidobactéria, e, portanto, apresentou a menor $(\mathrm{p}<0,05)$ contagem de células viáveis probióticas. Assim, a redução na contagem estaria relacionada a mais rápida dissolução e a maior higroscopicidade encontrada para a amostra em pó M2 (Tabela 2). Desta forma, os resultados obtidos para a contagem de células viáveis de bifidobactéria estariam relacionados às propriedades físicas do pó, como a dissolução e a higroscopicidade, bem como ao maior teor de sólidos totais e à maior viscosidade da solução de alimentação (Tabela 1). Pôde-se verificar que a presença do leite desnatado na microencapsulação de Bifidobacterium BB-12 contribuiu para a maior $(\mathrm{p}<0,05)$ contagem destas células viáveis probióticas. Contudo, as contagens de células viáveis probióticas ficaram acima do recomendado para um produto ser classificado de probiótico, ou seja, os valores obtidos foram maiores 
do que $6 \log$ UFC $\mathrm{g}^{-1}$. Estes valores para a contagem de probíoticos foram são essenciais, porque conforme Ananta, Volkert e Knorr (2005) a efetividade do consumo de alimentos probióticos está relacionada à sua viabilidade $\left(\geq 6 \log \mathrm{UFC} \mathrm{g}^{-1}\right)$. Enfim, estas contagens de probióticos estão de acordo com os resultados obtidos por Simpson et al. (2005).

Tabela 3 - Contagens de células viáveis de Bifidobacterium BB-12 nas soluções de alimentação e nas amostras em pó obtidas pelo método de spray drying

\begin{tabular}{lcc}
\hline & & Contagem de células viáveis $(\log$ UFC g-1) \\
\hline \multirow{3}{*}{ Solução de alimentação } & Controle & $9,20 \pm 0,53^{\mathrm{a}, \mathrm{b}}$ \\
& A1 & $9,05 \pm 0,59^{\mathrm{a}, \mathrm{b}}$ \\
& A2 & $9,39 \pm 0,17^{\mathrm{a}}$ \\
\hline \multirow{3}{*}{ Amostra em pó } & MC & $8,80 \pm 0,08^{\mathrm{b}}$ \\
& M1 & $8,77 \pm 0,55^{\mathrm{a}, \mathrm{b}, \mathrm{c}}$ \\
& M2 & $8,46 \pm 0,03^{\mathrm{c}}$ \\
\hline
\end{tabular}

Resultados expressos como média \pm desvio padrão, realizado em triplicata para cada amostra.

a,b,c Letras minúsculas sobrescritas diferentes indicam diferenças $(\mathrm{p}<0,05)$ entre as médias.

Controle, A1, e A2 representam as soluções de alimentação contendo $20 \mathrm{~g}$ de leite desnatado, $10 \mathrm{~g}$ de leite desnatado e $10 \mathrm{~g}$ de polidextrose, e $20 \mathrm{~g}$ de polidextrose, por $100 \mathrm{~mL}$ de água, respectivamente. MC, M1 e M2 representam as amostras em pó inoculadas com bifidobactérias, das soluções de alimentação Controle, A1 e A2, respectivamente.

Fonte: elaborado pelo autor (2018).

\section{CONCLUSÃO}

A utilização somente da polidextrose (prebiótico) resultou numa solução de alimentação com maior teor de sólidos totais e, portanto, mais viscosa. O estudo da morfologia confirmou a eficiência da microencapsulação de Bifidobacterium BB-12, com os agentes encapsulantes utilizados. Entretanto, foram observadas concavidades quando o leite desnatado foi empregado como agente encapsulante. Em relação ao tamanho, ao teor de umidade e à atividade de água, os três tipos de amostras produzidas estão de acordo com o que a literatura preconiza como parâmetros ideais para este tipo de produto. Contudo, as amostras em pó contendo microcápsulas produzidas com a mistura de leite desnatado e polidextrose, como agente encapsulante, demonstraram maior densidade aparente, enquanto as produzidas somente com polidextrose dissolveram mais rapidamente em água e foram mais higroscópicas. Tal comportamento pode ter sido responsável pela redução na contagem de bifidobactéria da amostra com microcápsulas produzidas com polidextrose, apesar de não ter sido observada diferenças entre as contagens das três soluções de alimentação. Ao final deste estudo, observou-se que as contagens de células viáveis de bifidobactéria, nas três amostras em pó, contendo microcápsulas produzidas com leite desnatado, leite com polidextrose e somente polidextrose, como agentes encapsulantes, ficaram acima do recomendado para um produto ser classificado de probiótico. Por fim, concluiu-se que uso da polidextrose, como agente encapsulante de Bifidobacterium BB-12, apresentou potencial protetivo no processo de microencapsulação por spray drying. 


\section{AGRADECIMENTOS}

Os autores gostariam de agradecer ao LCME-UFSC pelo suporte técnico durante o trabalho de microscopia eletrônica. Os autores agradecem ao CNPq (Conselho Nacional de Desenvolvimento Científico e Tecnológico) pelo apoio financeiro.

\section{REFERENCIAS}

AIDOO, R. P. et al. Industrial manufacture of sugar-free chocolates - Applicability of alternative sweeteners and carbohydrate polymers as raw materials in product development. Trends in Food Science and Technology, v. 32, p. 84-96, 2013.

ANAL, A.K.; STEVENS, W.F. Chitosan-alginate multilayer beads for controlled release of ampicillin. International Journal of Pharmaceutics, v. 290, p. 45-54, 2005.

ANANTA, E.; VOLKERT, M.; KNORR, D. Cellular injuries and storage stability of spray-dried Lactobacillus rhamnosus GG. International Dairy Journal, v.15, p.399-409, 2005.

ANNUNZIATA, A.; VECCHIO, R. Consumer perception of functional foods: A conjoint analysis with probiotics. Food Quality and Preference, v.28, p.348-355, 2013.

AVILA-REYES, S. V. et al. Protection of L. rhamnosus by spray-drying using two prebiotics colloids to enhance the viability. Carbohydrate Polymers, v. 102, p 423-430, 2014.

BÁEZ-GONZÁLEZ, J. G. et al. Effective moisture diffusivity in biopolymer drops by regular regime theory. Food Hydrocolloids, v. 18, 325-333, 2004.

CAI, Y. Z.; CORKE, H. Production and properties of spray-dried Amaranthus betacyanin pigments. Journal of Food Science, v. 65, 1248-1252, 2000.

CASIRAGHI, M. C. et al. Effects of a synbiotic milk product on human intestinal Ecosystem. Journal of Applied Microbiology, v. 103, p. 499-506, 2007.

CASTRO-CISLAGHI, F. P. et al. Bifidobacterium BB-12 microencapsulated by spray drying with whey: Survival under simulated gastrointestinal conditions, tolerance to $\mathrm{NaCl}$, and viability during storage. Journal of Food Engineering v.113, p. 186-193, 2012.

CHEN, K. N. et al. Optimization of incorporated prebiotics as coating materials for probiotic microencapsulation. Journal of Food Science, v.70, p. M260-M266, 2005.

CORCORAN, B. M. et al. Comparative survival of probiotic lactobacilli spray-dried in the presence of prebiotic substances. Journal of Applied Microbiology, v. 96, p.1024-1039, 2004. 
DE VOS, P. et al. Encapsulation for preservation of functionality and targeted delivery of bioactive food components. International Dairy Journal, v. 20, p. 292-302, 2010.

EL-TINAY, A. H.; ISMAIL, I. A. Effect of some additives and processes on the characteristics of agglomerated and granulated spray-dried Roselle powder. Acta Alimentaria Hungaricae, v. 14, $283-$ 295, 1985.

FANG, Z. X.; BHANDARI, B. Encapsulation of polyphenols - a review. Trends in Food Science \& Technology, v. 21, p. 510-523, 2010.

FAO/WHO. Probiotics in food. Health and nutritional properties and guidelines for evaluation: FAO Food and Nutrition Paper, Roma, 2006, 53p.

FÁVARO-TRINDADE, C. S. et al. The use of spray drying technology to reduce bitter taste of casein hydrolysate. Food Hydrocolloids, v. 24, p. 336-340, 2010.

FÁVARO-TRINDADE, C. S.; PINHO, S. C.; ROCHA, G. A. Revisão: Microencapsulação de ingredientes alimentícios. Brazilian Journal of Food Technology, v. 11, p. 103-112, 2008.

FRITZEN-FREIRE, C. B. et al. Effect of microencapsulation on survival of Bifidobacterium BB-12 exposed to simulated gastrointestinal conditions and heat treatments. LWT - Food Science and Technology, v. 50, p. 39-40, 2012 b.

FRITZEN-FREIRE, C. B. et al. Microencapsulation of bifidobacteria by spray drying in the presence of prebiotics. Food Research International, v. 45, p. 306-312, 2012a.

GOMES, C. R. et al. Influência de diferentes agentes de corpo nas características reológicas e sensoriais de chocolates diet em sacarose e light em calorias. Ciência e Tecnologia de Alimentos, v. 3, p. 614-623, 2007.

GRANATO, D. et al. Probiotic dairy products as functional foods. Comprehensive Reviews in Food Science and Food Safety, v. 9, p. 455-570, 2010.

HEIDEBACH, T.; FÖRST, P.; KULOZIK, U. Influence of casein-based microencapsulation on freezedrying and storage of probiotic cells. Journal of Food Engineering, v. 98, p. 309-316, 2010.

INSTITUTO ADOLFO LUTZ - IAL. Normas Analíticas do Instituto Adolfo Lutz: Médodos Físicoquímicos para análise de alimentos. $4^{\mathrm{a}}$. ed. São Paulo, 2008, 1020p.

KARIMI, R.; SOHRABVANDI, S.; MORTAZAVIAN, A. M. Review article: sensory characteristics of probiotic cheese. Comprehensive Reviews in Food Science and Food Safety, v.11, p. 437-452, 2012. 
KIM, S. J. et al. Effect of microencapsulation on viability and other characteristics in Lactobacillus acidophilus ATCC 43121. LWT - Food Science and Technology, v. 41, 493-500, 2008.

KOMATSU, T.R.; BURITI, F.C.A.; SAAD, S.M.I. Inovação, persistência e criatividade superando barreiras no desenvolvimento de alimentos probióticos. Brazilian Journal of Pharmaceutical Sciences, v. 44, p. 329-347, 2008.

KRASAEKOOPT, W.; BHANDARI, B.; DEETH, H. The influence of coating materials on some properties of alginate beads and survivability of microencapsulated probiotic bacteria. International Dairy Journal, v. 14, 737-743, 2004.

LIAN, W. C.; HSIAO, H. C.; CHOU, C. C. Survival of bifidobacteria after spray-drying. International Journal of Food Microbiology, v. 74, p.79-86, 2002.

MADENE, A. et al. Flavour encapsulation and controlled release - a review. International Journal of Food Science and Technology, v. 41, p. 1-21, 2006.

OKURO, P. K. et al. Co-encapsulation of Lactobacillus acidophilus with inulin or polydextrose in solid lipid microparticles provides protection and improves stability. Food Research Internation, v. 53, 2013.

OSORIO, J. et al. Effects of spray drying conditions and the addition of surfactants on the foaming properties of a whey protein concentrate. LWT - Food Science and Technology, v. 58, p. 109-115, 2014.

PALCZEWSKA-TULINSKA, M.; ORACZ, P. Selected physicochemical properties of hexamethylcyclotrisiloxane, octamethylcyclotetrasiloxane, and decamethylcyclopentasiloxane. Journal of Chemistry Engineering, v. 50, p. 1711-1719, 2005.

PERES, C. M. et al. Review on fermented plant materials as carriers and sources of potentially probiotic lactic acid bacteria e with an emphasis on table olives. Trends in Food Science and Technology, v. 26, 2012.

PINTO, S. S. et al. Effects of the addition of microencapsulated Bifidobacterium Bb-12 on the properties of frozen yogurt. Journal of Food Engineering, v. 111, p. 563-569, 2012.

PINTO, S. S. et al PINTO, S. S. et al. Influence of microencapsulation with sweet whey and prebiotics on the survival of Bifidobacterium-BB-12 under simulated gastrointestinal conditions and heat treatments. LWT - Food Science and Technology, v. 64, n. 2, p. 1004-1009, 2015.

PRASANNA, P. H. P.; GRANDISON, A. S.; CHARALAMPOPOULOS, D. Bifidobacteria in milk products: An overview of physiological and biochemical properties, exopolysaccharide production, selection criteria of milk products and health benefits. Food Research International, v. 55, p. 247$262,2014$. 
ROBERFROID, M. B. Inulin-Type Fructans: Functional Food Ingredients. The Journal of Nutrition, v.137, p 2493-2502, 2007.

ROKKA, S., RANTAMÄKI, P. Protecting probiotic bacteria by microencapsulation: challenges for industrial applications. European Food Research Technology v. 231, p. 1-12, 2010.

ROSS, R. P. et al. Overcoming the technological hurdles in the development of probiotic foods. Journal of Applied Microbiology, v. 98, 1410-1417, 2005.

SHAH, N. P. Functional cultures and health benefits. International Dairy Journal, v. 17, p. 12621277, 2007.

SIMPSON, P. J. et al. Intrinsic tolerance of Bifidobacterium species to heat and oxygen and survival following spray drying and storage. Journal of Applied Microbiology, v. 99, p. 493-501, 2005.

SOUKOULIS, C. et al. Stability os Lactobacillus rhamnosus GG in prebiotic edible films. Food Chemistry, v. 159, p. 302-308, 2014.

TONON, R. V. et al. Physicochemical and morphological characterisation of açai (Euterpe oleraceae Mart.) powder produced with different carrier agents. International Journal of Food Science and Technology, v.44, p.1950-1958, 2009.

VASILJEVIC, T.; SHAH, N.P. Probiotics - From Metchnikoff to bioactives. International Dairy Journal, v. 18, p. 714- 728, 2008.

VINDEROLA, C. G.; REINHEIMER, J. A. Culture media for the enumeration of Bifidobacterium bifidum and Lactobacillus acidophilus in the presence of yoghurt bacteria. International Dairy Journal, v. 9, 497-505, 1999.

VINDEROLA, G. et al. Growth of Lactobacillus paracasei A13 in Argentinian probiotic cheese and its impact on the characteristics of the product. International Journal of Food Microbiology, v. 135, p. 171-174, 2009.

VISSOTTO, F. Z.; GOMES, C. R.; BATISTA, B. J. L. Caracterização do comportamento reológico e da textura de chocolates sem sacarose. Brazilian Journal of Food Technology, v. 8, p. 107-111, 2005.

YING, D. Y. et al. Microencapsulated Lactobacillus rhamnosus GG powders: Relationship of powder physical properties to probiotic survival during storage. Journal of Food Science, v. 75, 2010. 